\title{
Therapeutic potential of policosanol in the concurrent management of dyslipidemia and non-alcoholic fatty liver disease
}

\author{
Mandeep K. Arora ${ }^{1,2}$, Sudhanshu Pandey ${ }^{1}$, Ritu Tomar ${ }^{2}$, Jagannath Sahoo², Dinesh Kumar and \\ Ashok Jangra ${ }^{1,3^{*}}$ (D)
}

\begin{abstract}
Background: High-fat diet (HFD) possesses a major cause of cardiovascular disease, and hepatosteatosis. Unfortunately, long-term use of statins has a theoretical possibility of worsening of hepatic histology in the patients with non-alcoholic fatty liver disease (NAFLD). The objective of the study was to explore hepatoprotective potential of policosanol as an alternative to statins in experimental NAFLD. For the same, young male Wistar rats were fed with HFD for 8 weeks to induce NAFLD. 48 adult Wistar rats were distributed into six investigational groups: normal control, HFD control, and four treatment groups, receiving policosanol (50 and $100 \mathrm{mg} / \mathrm{kg} /$ day), atorvastatin (30 mg/kg/day), and silymarin $(100 \mathrm{mg} / \mathrm{kg} /$ day) for 8 weeks along with HFD.

Result: HFD consumption caused profound hepatotoxicity evident by hepatic oxidative stress, increased Serum glutamic oxaloacetic transaminase (SGOT), Serum glutamic pyruvic transaminase (SGPT), Alkaline phosphatase (ALP), and bilirubin content. Treatment with policosanol $(100 \mathrm{mg} / \mathrm{kg})$ markedly reduced the elevated SGOT, SGPT, and ALP levels in HFD-fed rats. Moreover, policosanol significantly reduced hepatic oxidative stress manifest by reduced malondialdehyde (MDA) and increased glutathione (GSH) level. The treatment with policosanol $(100 \mathrm{mg} / \mathrm{kg})$ was found to be more active in attenuating the HFD-induced hepatotoxicity as compared to policosanol $(50 \mathrm{mg} / \mathrm{kg})$ and atorvastatin $(30 \mathrm{mg} / \mathrm{kg}$ ). Moreover, we observed that the hepatoprotective potential of policosanol was comparable to the silymarin.
\end{abstract}

Conclusions: The results of the study clearly indicated that the policosanol could be considered an intriguing approach for the treatment of NAFLD.

Keywords: Hepatotoxicity, Oxidative stress, Policosanol, Silymarin, Atorvastatin

\section{Background}

High-fat diet (HFD) is not only key risk factors for cardiovascular disease, but also a major cause for hepatosteatosis, also called non-alcoholic fatty liver disease (NAFLD) [1]. NAFLD is characterized by lipid deposition within hepatocytes due to over-consumption of

\footnotetext{
*Correspondence: ashokjangra123@gmail.com; ashok@cuh.ac.in; mmmarora2@gmail.com

${ }^{1}$ Department of Pharmacology, KIET School of Pharmacy, Ghaziabad, India

Full list of author information is available at the end of the article
}

HFD. The multifaceted signalling mechanisms have been identified to be associated with NAFLD, but the mainstream theory of NAFLD is based on "multiple parallel hits" hypothesis [2]. HFD or diabetes-induced insulin resistivity is the "first hit" leading to hepatic steatosis and the "second hit" is determined by the increased oxidative stress, that liable to steatohepatitis as well as fibrosis. The relationship between type 2 diabetes mellitus (T2DM) and NAFLD is complex, and bidirectional [3, 4]. Apart from the increased prevalence of NAFLD in T2DM, NAFLD has been reported to increase the possibility of developing T2DM. With ultrasound studies and biopsy 
of liver, a clinical investigation reported that the prevalence of diabetes is approximately three-times higher in the patients with NAFLD in comparison to the general population [5]. In addition, the relationship between the cardiovascular diseases and NAFLD is also bidirectional as thrombosis in small intrahepatic veins, was observed to elicit hepatic remodelling and thrombotic events are frequently present in the NAFLD patients, responsible for more advanced fibrosis [6]. On the other hand, evidences also suggest that the patients with NAFLD have a greater incidence of cardiovascular disease, compared to the general population [7]. Thereby, if untreated, this fatty infiltration in the liver not only increases the metabolic abnormality associated with cardiovascular risk but also further leads to cirrhosis and liver failure.

Statins, $\beta$-Hydroxy $\beta$-methylglutaryl-CoA (HMG-CoA) reductase inhibitors, are considered as mainstay for the management of hyperlipidemia [8]. As patients with NAFLD show a high risk for the cardiovascular disorders, statins are recommended to patients with NAFLD, and dyslipidemia. However, in regard to the long-term use of statins, questions have been raised by the researchers for the theoretical possibility of worsening of hepatic histology in the patients with NAFLD [9]. In addition, a clinical instigation raised the question regarding the efficacy of statins in the management of NAFLD by demonstrating that simvastatin treatment did not cause any significant improvement in serum aminotransferase levels, necroinflammatory activity, hepatic steatosis, or stages of fibrosis in nonalcoholic steatohepatitis (NASH) [9]. Even several lines of evidence revealed that other alternative hypolipidemic such as resins, nicotinic acids or fibric acid derivatives are also associated with the adverse effects [9, 10]. Thus, it is essential to develop efficacious and safe therapeutic intervention to prevent HFD induced-dyslipidemia and associated NAFLD.

Policosanol, a mixture of some aliphatic primary alcohols [Octacosanol (62 9\%), Tricosanol (12.6\%), Hexacosanol (6.2\%)] found in wax of sugar cane (Saccharum officinarum) [11]. Policosanol has been demonstrated to reduce the serum total cholesterol (TC) and low density lipoprotein (LDL) and restores the level of high density lipoprotein (HDL) $[12,13]$. The hypolipidemic potential of policosanol is attributed to down-regulating the HMGCoA reductase [14]. In addition, policosanol has been reported to reduce the lipid peroxidation in rats [15]. Furthermore, policosanol has antithrombotic property as it inhibits the formation of thromboxane A2 (TXA2) [16]. Moreover, policosanol possesses potent antioxidant property by reducing the formation of reactive oxygen species (ROS) through Reduced nicotinamide adenine dinucleotide phosphate (NADPH) oxidase inhibition and stimulation of the activities of catalase and superoxide dismutase [14, 17]. Policosanol also inhibits proprotein convertase subtilisin/kexin type 9 (PCSK9), an enzyme responsible for degradation of LDL receptors which results in the reduction of LDL level [18]. Therefore, by considering the hypolipidemic, anti-thrombotic and antioxidant activities of policosanol, the study was aimed to explore the effect of policosanol in HFD-induced dyslipidemia and associated hepatotoxicity in rats, comparing the hypolipidemic and hepatoprotective activities of policosanol with atorvastatin and silymarin.

\section{Methods}

\section{Drugs and chemicals}

Policosanol was procured from Arjuna Natural Extracts Ltd., Kerala. Atorvastatin and Silymarin were purchased from (Sigma Chemicals Co. U.S.A.). Total cholesterol (TC) (120194), triglyceride (TG) (120211), high-density lipoprotein (HDL) (121260), SGOT (120204), SGPT (120208), ALP (BLT00003), Serum bilirubin (120244) estimation kits were purchased from ERBA (Transasia Bio-Medical Diagnostic Reagent Kit, Solan, India). All the chemicals purchased for current study, were of analytical grade.

\section{Animals}

The male adult Wistar rats $(200 \pm 20 \mathrm{~g})$ of 6 weeks' old were purchased from AIIMS, New Delhi, India. The protocol was reviewed and approved by the Institutional Animal Ethics committee (IAEC). Rats were housed in cages at temperature $\left(25 \pm 2{ }^{\circ} \mathrm{C}\right)$ and controlled humidity $(65 \pm 10 \%)$ with $12 \mathrm{~h}$ light/dark cycle. Food, and potable water remained ad libitum throughout the study. The study was executed (Approval no. IAEC/KSOP/E/16/10) as per the guidelines of Committee for the Purpose of Control and Supervision of Experimentation on Animals (CPCSEA), New Delhi.

\section{Preparation of high-fat diet}

The high-fat diet was prepared using powdered normal pellet diet $(36.50 \%)$, cholesterol $(1 \%)$, casein $(25 \%)$, lard (31\%), vitamin and mineral mix $(6 \%)$, yeast powder $(0.1 \%)$, DL-Methionine (0.3\%), and sodium chloride $(0.1 \%)$ in a fixed ratio described by Srinivasan et al. [19]

\section{Experimental protocol}

The adult male Wistar rats $(220 \pm 20 \mathrm{~g})$ were allocated into six experimental groups and each group comprised of 8 animals. Policosanol was suspended in 2\% Tween-20/ water and administered orally at dose of 50 and $100 \mathrm{mg} /$ $\mathrm{kg}$ from day- 1 to day- 56 in different experimental groups. An earlier study also demonstrated the hepatoprotective effect of policosanol in Carbon Tetrachloride-induced liver injury in rats [20]. The doses of atorvastatin and 
silymarin were selected on the basis of previous studies $[21,22]$.

Group I (Normal control): animals were fed on standard pellet diet and potable water and administered $0.5 \%$ CMC solution in distilled water for 8 weeks.

Group II (Disease control): animals were fed on HFD, and potable water for 8 weeks.

Group III (HFD+policosanol-50 $\mathrm{mg} / \mathrm{kg}$ ): animals were fed on HFD and were treated with policosanol $(50 \mathrm{mg} / \mathrm{kg}$; p.o.) for 8 weeks.

Group IV (HFD + policosanol-100 mg/kg): animals were fed on HFD and were treated with policosanol $(100 \mathrm{mg} / \mathrm{kg}$; p.o.) for 8 weeks.

Group V (HFD + atorvastatin-30 $\mathrm{mg} / \mathrm{kg}$ ): animals were fed on HFD and were treated with atorvastatin $(30 \mathrm{mg} / \mathrm{kg}$; p.o.) for 8 weeks.

Group VI (HFD + silymarin-100 $\mathrm{mg} / \mathrm{kg}$ ): animals were fed on HFD and were treated with silymarin (100 mg/kg; p.o.) for 8 weeks.

After the completion of eight weeks, animals were first weighed and then sacrificed through cervical dislocation. Blood samples were collected to separate the serum through a centrifugation ( $2500 \mathrm{rpm}$ for $10 \mathrm{~min}$ ) using a centrifuge. Liver was isolated quickly, then washed in $0.9 \% \mathrm{NaCl}$ solution, weighed and finally homogenized $\left(10,000 \mathrm{rpm}\right.$ for $15 \mathrm{~min}$ at $\left.4{ }^{\circ} \mathrm{C}\right)$ in $0.1 \mathrm{M}$ Tris- $\mathrm{HCl}$ buffer at $\mathrm{pH} 7.4$ through homogenizer. The collected serum and liver homogenate were stored in $-20{ }^{\circ} \mathrm{C}$ used for further biochemical analysis.

\section{Estimation of lipid profile}

The TC (Cat. No. BLT00036), TG (Cat. No. BLT00024), and HDL (Cat. No. BLT00028) were estimated by using commercially available kits (ERBA, Transasia BioMedical Diagnostic Reagent Kit, Solan, India). The kit protocols provided by the company were followed to determine the TC, TG and HDL.

\section{Estimation of atherogenic index}

Atherogenic index (AI) is an important predictor for the cardiovascular risk assessment [23]. It was measured by using the following formula- "AI=(TC-HDL)/HDL".

\section{Assessment of liver function}

The HFD-induced NAFLD was assessed biochemically by estimating SGPT (Cat. No. BLT00053), SGOT (Cat. No. BLT00051), alkaline phosphatase (Cat. No. BLT00004) and total bilirubin level in the serum. SGPT, SGOT and ALP were estimated by the method provided with the commercially available kit (ERBA, Transasia Bio-Medical diagnostic reagent kit). The total bilirubin level was estimated by the protocol available with Agappe diagnostic kit (Mumbai).

\section{Determination of oxido-nitrosative stress}

Tissue lipid peroxidation was assessed using the method of Okhawa et al., 1979 as described in a previous study $[24,25]$. One $\mathrm{ml}$ of the tissue homogenate was mixed with $0.2 \mathrm{~mL}$ of $4 \%$ sodium dodecyl sulphate, $1.5 \mathrm{~mL}$ of $20 \%$ acetic acid in $0.27 \mathrm{M} \mathrm{HCl}(\mathrm{pH} 3.5)$ and by addition of $15 \mathrm{~mL}$ of $0.8 \%$ thiobarbituric acid (pH 7.4). The resulting mixture was kept on hot water bath at $95^{\circ} \mathrm{C}$ for $1 \mathrm{~h}$. 1,1,3,3-tetraethoxy propane was taken as a standard. After centrifugation $(5000 \times g$ for 5 min with the help of centrifuge), the intensity of pink colour obtained after heating was compared with a blank reagent at $532 \mathrm{~nm}$. The concentration was expressed as nanomoles of malondialdehyde (MDA) per mg of protein. The reduced glutathione (GSH) level was assessed by the method described by Beutler et al. [26]. The equal proportions of liver homogenate and trichloroacetic acid $(10 \%, \mathrm{w} / \mathrm{v})$ were mixed and the mixture was centrifuged at $1000 \times g$ for $10 \mathrm{~min}$ at a temperature $4{ }^{\circ} \mathrm{C}$. After obtaining the supernatant, it was mixed with $2 \mathrm{~mL}$ of $0.3 \mathrm{M}$ disodium hydrogen phosphate, and $250 \mu \mathrm{L}$ of $0.001 \mathrm{M}$ (5,5-dithiobis-(2-nitrobenzoic acid) DTNB. The absorbance of the finally obtained yellow-colored solution was taken against the blank at $412 \mathrm{~nm}$. The concentration of GSH was represented as $\mu$ mole/mg of protein. The nitrite level was quantified as described by Green et al. [27]. Equal volumes of liver homogenate and the Griess reagent were mixed. The mixture was kept at dark place for $20 \mathrm{~min}$. The absorbance was noted against blank at $540 \mathrm{~nm}$. The results were represented as $\mu \mathrm{mol} / \mathrm{mg}$ of protein.

\section{Statistical analysis}

All obtained values expressed as mean \pm standard deviation. The data obtained was statistically analysed using one-way ANOVA, followed by Tukey's multiple comparison tests. The $p<0.05$ was considered to be statistically significant. GraphPad Prism 5 software (GraphPad Inc., La Jolla, CA) was used for statistical analysis of data.

\section{Results}

All the parameters were measured at the end of 8 weeks in normal and treated rats. Rats fed on HFD showed profound hyperlipidemia and hepatotoxicity after eight weeks. Less than $5 \%$ of mortality was noted in rats fed on HFD with or without the drug treatments.

\section{Effect of pharmacological interventions on lipid profile}

We found significant $(p<0.001)$ elevation of serum TC and TG level in HFD-fed rats as compared to normal control (Table 1). On the other hand, HFD fed animals 
Table 1 Effect of policosanol, atorvastatin, and silymarin treatments on serum triglyceride, total cholesterol, high density lipoproteins $(\mathrm{HDL})$, and atherogenic index in HFD-fed animals

\begin{tabular}{|c|c|c|c|c|c|c|}
\hline Serum parameters & Normal control & Disease control (HFD) & $\begin{array}{l}\text { Policosanol } 50 \\
(\mathrm{mg} / \mathrm{kg})+\text { HFD }\end{array}$ & $\begin{array}{l}\text { Policosanol } 100 \\
(\mathrm{mg} / \mathrm{kg})+\text { HFD }\end{array}$ & $\begin{array}{l}\text { Atorvastatin30 } \\
(\mathrm{mg} / \mathrm{kg})+\mathrm{HFD}\end{array}$ & $\begin{array}{l}\text { Silymarin } 100 \\
(\mathrm{mg} / \mathrm{kg})+\mathrm{HFD}\end{array}$ \\
\hline Triglycerides (mg/dl) & $98.56 \pm 9.18$ & 196.48土18.65@@@ & $164.15 \pm 20.11^{*}$ & $116.84 \pm 13.04^{* * *}$ & $136.45 \pm 13.14^{* * *}$ & $141.23 \pm 15.56^{* * *}$ \\
\hline Total cholesterol (mg/dl) & $58.94 \pm 6.41$ & 88.95土11.29@@@ & $77.46 \pm 8.38$ & $64.96 \pm 8.16^{* * *}$ & $66.05 \pm 6.43^{* * *}$ & $70.86 \pm 8.38^{* *}$ \\
\hline $\begin{array}{l}\text { High density lipoprotein } \\
(\mathrm{mg} / \mathrm{dl})\end{array}$ & $36.15 \pm 3.67$ & 26.04士2.86@@@ & $31.06 \pm 3.51$ & $34.92 \pm 3.32^{* *}$ & $34.59 \pm 4.06^{* *}$ & $32.48 \pm 3.65^{*}$ \\
\hline Atherogenic Index & $0.52 \pm 0.06$ & $2.01 \pm 0.28^{@ @ @ ~}$ & $1.74 \pm 0.17$ & $0.87 \pm 0.11^{* * *}$ & $0.91 \pm 0.12^{* * *}$ & $1.18 \pm 0.13^{* * *}$ \\
\hline
\end{tabular}

Data are represented as mean $\pm \mathrm{SD}(n=6)$

$@ @ @<0.001$ compared with the normal control group

${ }^{*} p<0.05$ compared with the HFD group

${ }^{* *} p<0.01$ compared with the HFD group

${ }^{* * *} p<0.001$ compared with the HFD group

showed significantly $(p<0.001)$ reduction in the serum HDL level as compared to normal control. Policosanol $(50$ and $100 \mathrm{mg} / \mathrm{kg})$ treatment significantly $(p<0.05$, $p<0.001$ respectively) reduced serum TC and TG level in HFD-fed animals. Moreover, atorvastatin and silymarin treatment significantly $(p<0.001)$ prevented the HFDinduced alteration in lipid levels (Table 1).

\section{Effect of pharmacological interventions on atherogenic index}

The atherogenic index based on the serum level of TC and HDL was noted significantly $(p<0.001)$ high in HFD fed animals as compared to the normal control group. Administration of policosanol $(100 \mathrm{mg} / \mathrm{kg})$, atorvastatin and silymarin significantly $(p<0.001)$ restored the atherogenic index in HFD-fed animals (Table 1).

\section{Effect of pharmacological interventions on serum AST, ALT, and ALP levels}

HFD consumption caused a marked $(p<0.001)$ surge in the serum concentration of AST, ALT, and ALP levels (Table 1). However, policosanol $(100 \mathrm{mg} / \mathrm{kg})$, atorvastatin, and silymarin treated groups presented significant $(p<0.001)$ fall in the AST level as compared to the HFD group. Atorvastatin and silymarin treated groups also showed marked $(p<0.001)$ decline in AST level. Moreover, Policosanol $(100 \mathrm{mg} / \mathrm{kg})$, atorvastatin and silymarin significantly $(p<0.001, p<0.01, p<0.001$ respectively) reduced the ALT level in HFD-fed animals. However, Policosanol-50 mg/kg failed to reduce the elevated levels of ALT, AST and ALP in the HFD group (Table 2).

\section{Effect of pharmacological interventions on serum bilurubin} We found that bilurubin level was markedly $(p<0.001)$ increased in rats fed on HFD. Policosanol $(100 \mathrm{mg} / \mathrm{kg})$, atorvastatin and silymarin treated groups showed significant $(p<0.001, p<0.01$, and $p<0.001$ respectively) decrease in the bilirubin level as compared to the HFD group. Policosanol-50 mg/kg failed to produce a substantial outcome on bilirubin level in HFD-fed rats.

\section{Effect of pharmacological interventions on total protein and albumin in serum}

We found that HFD consumption significantly $(p<0.001)$ decreased serum concentration of total protein in the HFD group as compared to the normal control (Fig. 1a).

Table 2 Effect of policosanol, atorvastatin, and silymarin treatments on AST, ALT, and ALP in the HFD-fed animals

\begin{tabular}{lcccccc}
\hline Serum parameters & Normal control & Disease control (HFD) & $\begin{array}{l}\text { Policosanol 50 } \\
\text { (mg/kg)+HFD }\end{array}$ & $\begin{array}{l}\text { Policosanol 100 } \\
\text { (mg/kg)+HFD }\end{array}$ & $\begin{array}{l}\text { Atorvastatin30 } \\
\text { (mg/kg)+HFD }\end{array}$ & $\begin{array}{l}\text { Silymarin 100 } \\
\text { (mg/kg)+HFD }\end{array}$ \\
\hline AST (IU/L) & $45.45 \pm 6.10$ & $89.46 \pm 9.89^{@ @ @ ~}$ & $74.32 \pm 9.01$ & $52.56 \pm 7.29^{* * *}$ & $59.84 \pm 6.54^{* * *}$ & $56.18 \pm 5.98^{* * *}$ \\
ALT (IU/L) & $41.52 \pm 5.69$ & $78.14 \pm 9.09^{@ @ @ ~}$ & $70.65 \pm 6.92$ & $60.83 \pm 12.18^{* *}$ & $52.42 \pm 6.77^{* * *}$ & $50.64 \pm 5.46^{* * *}$ \\
ALP (IU/L) & $98.48 \pm 15.64$ & $167.51 \pm 22.43^{@ @ @ ~}$ & $150.83 \pm 19.88$ & $134.81 \pm 13.13^{*}$ & $120.12 \pm 13.89^{* * *}$ & $125.56 \pm 16.92^{* *}$ \\
BILIRUBIN (IU/L) & $0.76 \pm 0.18$ & $1.77 \pm 0.31^{@ @ @ ~}$ & $1.39 \pm 0.33$ & $0.101 \pm 0.27^{* * *}$ & $1.19 \pm 0.11^{* *}$ & $0.91 \pm 0.18^{* * *}$ \\
\hline
\end{tabular}

Data are represented as mean $\pm \mathrm{SD}(n=6)$

$@ @ @<0.001$ compared with the normal control group

${ }^{*} p<0.05$ compared with the HFD group

${ }^{* *} p<0.01$ compared with the HFD group

${ }^{* * *} p<0.001$ compared with the HFD group 

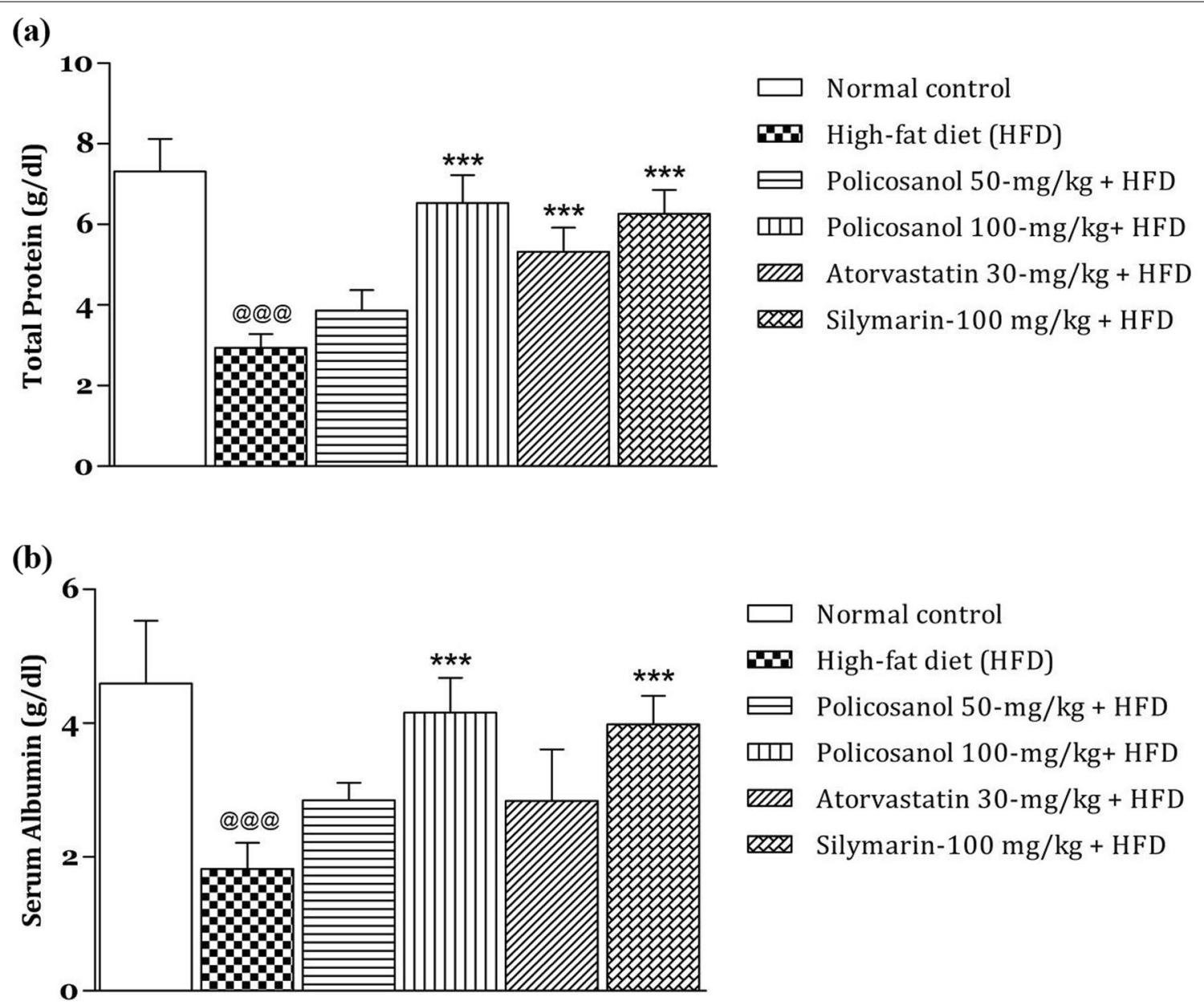

Fig. 1 Effect of Policosanol, Atorvastatin, and Silymarin treatments on serum. a Total protein, b Albumin in HFD-fed animals. All values are represented as mean \pm SD $(n=6)$. ${ }^{@} p<0.001$ as compared with normal control animals; ${ }^{* * *} p<0.001$ as compared with HFD group

Treatment with low dose of policosanol did not produced any noteworthy outcome on serum total protein and albumin levels. However, treatment with policosanol $(100 \mathrm{mg} / \mathrm{kg})$, atorvastatin and silymarin markedly increased the serum concentration of total protein in HFD-fed rats. The serum level of albumin was significantly $(p<0.001)$ decreased after consumption of HFD (Fig. 1b). However, higher dose of policosanol and silymarin significantly $(p<0.001)$ restored the serum albumin level. Low-dose policosanol and atorvastatin failed to produce any noteworthy effect on serum albumin level in rats.

\section{Effect of pharmacological interventions} on oxidative-nitrosative stress markers in the liver

Thiobarbituric acid reactive substances (TBARS), a marker of oxidative stress was found significantly $(p<0.001)$ elevated in the liver of HFD-fed rats (Fig. 2a).
Treatment with policosanol $(100 \mathrm{mg} / \mathrm{kg})$, atorvastatin, and silymarin significantly $(p<0.001, p<0.05$, and $p<0.001$ respectively) reduced TBARS level in HFDfed rats. Additionally, we found that HFD consumption caused significant $(p<0.001)$ decline in GSH level in comparison to the normal control group (Fig. 2b). However, policosanol $(100 \mathrm{mg} / \mathrm{kg})$, atorvastatin, and silymarin treated groups presented significant $(p<0.001$, $p<0.01$, and $p<0.001$ respectively) augmentation of hepatic GSH as compared to the HFD group. Nitrite level was noted significantly $(p<0.001)$ increased in the HFD group comparative to the normal control group (Fig. 2c). Policosanol (100 mg/kg), and silymarin treated groups showed significant $(p<0.001)$ decrease in hepatic nitrite level as compared to the HFD group. However, a low dose of policosanol failed to produce any significant result on hepatic oxido-nitrosative level. 

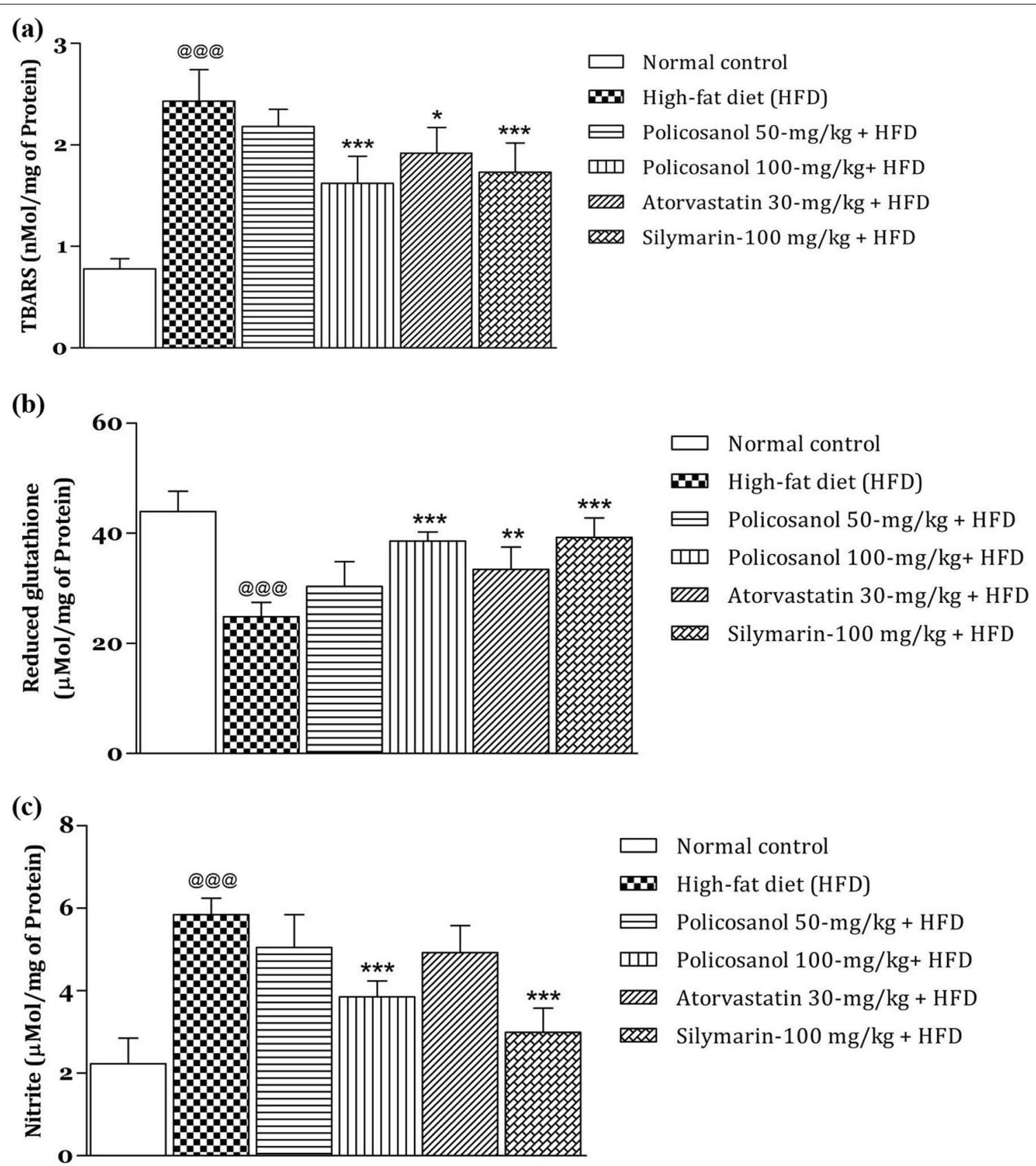

Fig. 2 Effect of policosanol, atorvastatin, and silymarin treatments on oxido-nitrosative parameters: a TBARS, b reduced glutathione, $\mathbf{c}$ nitrite level in HFD-fed animals. All values are represented as mean $\pm S D(n=6)$. $@ @ ~ p<0.001$ as compared with normal control animals; ${ }^{*} p<0.05,{ }^{* *} p<0.01$, ${ }^{* * *} p<0.001$ as compared with HFD group

\section{Discussion}

The HFD is supposed to be an independent risk factor in the induction and development of NAFLD. In recent years, many reports are available where attempts are being made to manage HFD-associated NAFLD. Among the available pharmacological treatment including insulin sensitizers, antioxidants, lipid-lowering drugs, ACE inhibitors, pentoxyphylline or other herbal remedies, the lipid-lowering drugs, especially statins, have taken the lead in the term of management of NAFLD as well as associated cardiovascular disorders (CVD). However, the toxicity related to statins raised a need to explore natural hypolipidemic agent for the management of HFD associated with NAFLD and dyslipidemia. In the present 
study, HFD-induced NAFLD and dyslipidemia model was employed to investigate the therapeutic potential of policosanol. We found that HFD increases the number of chylomicrons in the intestine that leads to augmentation of free fatty acid (FFA) in circulation that is taken up by the liver. Thus, under the influence of HFD, the liver exhibits characteristic fatty infiltration that associates with the initiation of dyslipidemia and subsequent initiation of insulin resistance, that results in excessive lipid accumulation and finally liver damage. In the present study, rats fed on HFD showed increase in adipose tissue mass along with increase in the circulating level of TC and TG. Treatment with policosanol $100 \mathrm{mg} / \mathrm{kg} /$ day for eight weeks significantly reduced HFD-induced elevated levels of serum TG and TC. In a dose-dependent manner, policosanol attenuated the increased adipose tissue mass, therefore reduced HFD associate obesity. The observed hypolipidemic effect of policosanol was corroborated with previous findings $[28,29]$. It is worth mentioning that HFD-induced NAFLD is independently linked to cardiovascular risk and patients with NAFLD have a greater frequency of cardiovascular disease [30,31]. The present study supports this contention as marked increase in atherogenic index was noted in the HFD-fed rats. Treatment with high-dose of policosanol significantly decreased the atherogenic index. A previous clinical study also suggested the potential of policosanol in the treatment of hyperlipidemia with NAFLD [32]. In addition, a recent study demonstrated the potential of policosanol against obesity and metabolic disorders by increasing brown adipose tissue activity through augmentation of Free fatty acid receptors 4 (FFAR4) expression, a gene encoding polyunsaturated fatty acid receptor [33].

A number of enzymes are biosynthesized and stored in hepatic cells. Liver serum ALT and AST are considered as reliable markers of liver functioning. The elevated serum levels of AST and ALT signifies the impairment in hepatic structural integrity, and level raised into circulation as a consequence of cellular damage [34, 35]. HFD feeding results in marked elevation of both the enzymes as a result of cell lyses. The damaged cell liberates these enzymes into systematic circulation. In the present study, significant elevation of all these enzymes were observed that indicates hepatic cell necrosis. Treatment with highdose policosanol reversed the activity of transaminases and restored them towards normal, depicting a marked protective effect. ALP found in the cells, lining the biliary ducts. Plasma ALP level may be note to be raised during obstruction in large bile duct/ intra-hepatic cholestasis/ and infiltrative ailments of the liver. In the present study, HFD feeding resulted in marked elevation of serum ALP levels which represent the alteration in the integrity of the hepatobiliary system. Treatment with high-dose policosanol reversed the elevated levels of serum ALP in rats on HFD which further confirms the hepatoprotective property of policosanol. Bilirubin produced in the reticulo-endothelial tissue from the catabolism of heme pigments is carried to the liver, and then it conjugates with the glucuronic acid. The bilirubin glucuronide is much more soluble in aqueous medium than the free (unconjugated) bilirubin. Thus, hyper-bilirubinaemia is considered as one of the outmost indicators of the severity of necrosis and hepatic damage [36].

The protein contents in the plasma of HFD-bearing animals appear to be associated with impaired hepatic function resulting from infiltration with lipid peroxides. The administration of policosanol $(100 \mathrm{mg} / \mathrm{kg})$ to the HFD group restored the protein levels to a normal level and also in comparison with the reference drug silymarin; thereby, provide direct evidence of hepatoprotective potential of policosanol in the HFD-induced hepatotoxicity. Further, lipid peroxidation is known as one of the key causes of HFD-induced liver damage, and is link to generation of free radical derivatives of fatty acid oxidation [37]. Thereby, the inhibition of free radical's generation is vital in terms of shielding the liver from HFD-induced damage. GSH, an endogenous antioxidant plays an important role in combating oxidative stress [38]. In the current study, HFD elevated the TBARS level with reduction of GSH level in the liver. Accordingly, these results reflect the oxidative imbalance in the liver after HFD consumption. High dose of policosanol treatment restored the TBARS and GSH level. Several studies had demonstrated the antioxidant potential of policosanol [39]. This study, for the first time, exhibits policosanol antioxidant property in HFD-induced hepatic damage. Nitrite content indirectly reflects nitric oxide level. Nitric oxide readily reacts with free radicals and forms a strong oxidant, i.e., peroxynitrite. Peroxynitrite, in turn, causes protein and DNA damage and impairment of oxidative phosphorylation that finally leads to hepatocellular cell death [40]. Moreover, a high level of nitrite in the HFD group as compared to the normal control group. Thus, elevated level of nitrite further exacerbates oxidative stress-induced hepatic damage. The study results indicated policosanol and silymarin were found to be effective against HFD-induced nitrosative stress.

\section{Conclusions}

In conclusion, our experimental data revealed the protective effects of policosanol are comparable with silymarin against HFD-evoked hepatotoxicity. This protective effect is likely due to the inhibition of oxidative and nitrosative stress and restoration of the atherogenic index. Hence, the current investigation suggested that policosanol 


\section{could be an intriguing therapeutic approach for the treat- ment of HFD-induced hepatotoxicity.}

\begin{abstract}
Abbreviations
Al: Atherogenic index; ALP: Alkaline phosphatase; ALT: Alanine transaminase; AST: Aspartate aminotransferase; CVD: Cardio vascular disorders; FFA: Free fatty acid; GSH: Reduced glutathione; HDL: High density lipoprotein; HFD: High-fat diet; HMG CoA: Hydroxy-methyl-glutaryl coenzyme A; LDL: Low density lipoprotein; MDA: Malondialdehyde; NAFLD: Non-alcoholic fatty liver disease; ROS: Reactive oxygen species; SGOT: Serum glutamic-oxaloacetic transaminase; SGPT: Serum glutamic-pyruvic transaminase; T2DM: Type 2 diabetes mellitus; TBARS: Thiobarbituric acid reactive substances; TC: Total cholesterol; TG: Triglycerides.
\end{abstract}

\section{Acknowledgements}

Not applicable.

\section{Authors' contributions}

MKA, and AJ conceived the manuscript, conducted the review, and wrote the first draft. SP, RT, JS, and DK revised and approved the manuscript. All authors read, corrected, and approved the final manuscript.

\section{Funding}

Self-financed.

Availability of data and materials

Not applicable. All included in paper.

\section{Declarations}

\section{Ethics approval and consent to participate}

The protocol was approved by the Institutional Animal Ethics Committee (IAEC), KIET, Ghaziabad (Approval no. IAEC/KSOP/E/16/10).

\section{Consent for publication}

Not applicable.

\section{Competing interests}

The authors declare no competing interests.

\section{Author details}

${ }^{1}$ Department of Pharmacology, KIET School of Pharmacy, Ghaziabad, India. ${ }^{2}$ School of Pharmaceutical and Population Health Informatics, DIT University, Dehradun, India. ${ }^{3}$ Present Address: Department of Pharmaceutical Sciences, Central University of Haryana, Mahendergarh, Haryana, India.

Received: 30 July 2021 Accepted: 4 January 2022

Published online: 15 January 2022

\section{References}

1. Kumar D, Dwivedi DK, Lahkar M, Jangra A (2019) Hepatoprotective potential of 7, 8-Dihydroxyflavone against alcohol and high-fat diet induced liver toxicity via attenuation of oxido-nitrosative stress and NF-KB activation. Pharmacol Rep 71:1235-1243

2. Chen G, Ni Y, Nagata N, Xu L, Ota T (2016) Micronutrient antioxidants and nonalcoholic fatty liver disease. Int J Mol Sci 17:1379

3. Anstee QM, Targher G, Day CP (2013) Progression of NAFLD to diabetes mellitus, cardiovascular disease or cirrhosis. Nat Rev Gastroenterol Hepatol 10:330-344

4. Firneisz G (2014) Non-alcoholic fatty liver disease and type 2 diabetes mellitus: the liver disease of our age? World J Gastroenterol 20:9072-9089

5. Williams CD, Stengel J, Asike MI, Torres DM, Shaw J, Contreras M, Landt CL, Harrison SA (2011) Prevalence of nonalcoholic fatty liver disease and nonalcoholic steatohepatitis among a largely middle-aged population utilizing ultrasound and liver biopsy: a prospective study. Gastroenterology 140:124-131

6. Papatheodoridis GV, Chrysanthos N, Cholongitas E, Pavlou E, Apergis G, Tiniakos DG, Andrioti E, Theodossiades G, Archimandritis AJ (2009) Thrombotic risk factors and liver histologic lesions in non-alcoholic fatty liver disease. J Hepatol 51:931-938

7. Valbusa F, Agnoletti D, Scala L, Grillo C, Arduini P, Bonapace S, Calabria S, Scaturro G, Mantovani A, Zoppini G, Turcato E, Maggioni AP, Arcaro G, Targher G (2018) Non-alcoholic fatty liver disease and increased risk of all-cause mortality in elderly patients admitted for acute heart failure. Int J Cardiol 265:162-168

8. Blumenthal RS (2000) Statins: effective antiatherosclerotic therapy. Am Heart J 139:577-583

9. Bhardwaj SS, Chalasani N (2007) Lipid-lowering agents that cause druginduced hepatotoxicity. Clin Liver Dis 11:597-613

10. Zodda D, Giammona R, Schifilliti S (2018) Treatment strategy for dyslipidemia in cardiovascular disease prevention: focus on old and new drugs. Pharmacy (Basel) 6:10

11. Perez Y, Mas R, Oyarzabal A, Jiménez S, Molina V (2013) Effects of policosanol (sugar cane wax alcohols) and D-003 (sugarcane wax acids) on cyclooxygenase (COX) enzyme activity in vitro. Int J Pharm Sci Rev Res 19:18-23

12. Castano G, Mas R, Fernández L, IIInait J, Mesa M, Alvarez E, Lezcay M (2003) Comparison of the efficacy and tolerability of policosanol with atorvastatin in elderly patients with type II hypercholesterolaemia. Drugs Aging 20:153-163

13. Greyling A, De Witt C, Oosthuizen W, Jerling JC (2006) Effects of a policosanol supplement on serum lipid concentrations in hypercholesterolaemic and heterozygous familial hypercholesterolaemic subjects. Br J Nutr 95:968-975

14. McCarty MF (2005) An ezetimibe-policosanol combination has the potential to be an OTC agent that could dramatically lower LDL cholesterol without side effects. Med Hypotheses 64:636-645

15. Menéndez R, Fraga V, Amor AM, González RM, Más R (1999) Oral administration of policosanol inhibits in vitro copper ion-induced rat lipoprotein peroxidation. Physiol Behav 67:1-7

16. Arruzazabala ML, Carbajal D, Mas R, Molina V, Valdes S, Laguna A (1994) Cholesterol-lowering effects of policosanol in rabbits. Biol Res 27:205-208

17. Ohta Y, Ohashi K, Matsura T, Tokunaga K, Kitagawa A, Yamada K (2008) Octacosanol attenuates disrupted hepatic reactive oxygen species metabolism associated with acute liver injury progression in rats intoxicated with carbon tetrachloride. J Clin Biochem Nutr 42:118-125

18. Guo YL, Xu RX, Zhu CG, Wu NQ, Cui ZP, Li JJ (2014) Policosanol attenuates statin-induced increases in serum proprotein convertase subtilisin/kexin type 9 when combined with atorvastatin. Evid Based Complement Altern Med 2014:926087

19. Srinivasan K, Viswanad B, Asrat L, Kaul CL, Ramarao P (2005) Combination of high-fat diet-fed and low-dose streptozotocin-treated rat: a model for type 2 diabetes and pharmacological screening. Pharmacol Res 52:313-320

20. Noa M, Mendoza S, Más R, Mendoza N (2003) Effect of policosanol on carbon tetrachloride-induced acute liver damage in sprague-dawley rats. Drugs R D 4:29-35

21. Funatsu T, Kakuta H, Takasu T, Miyata K (2002) Atorvastatin increases hepatic fatty acid beta-oxidation in sucrose-fed rats: comparison with an MTP inhibitor. Eur J Pharmacol 455:161-167

22. Chen IS, Chen YC, Chou CH, Chuang RF, Sheen LY, Chiu CH (2012) Hepatoprotection of silymarin against thioacetamide-induced chronic liver fibrosis. J Sci Food Agric 92(7):1441-1447

23. Munshi RP, Joshi SG, Rane BN (2014) Development of an experimental diet model in rats to study hyperlipidemia and insulin resistance, markers for coronary heart disease. Indian J Pharmacol 46(3):270-276

24. Ohkawa H, Ohishi N, Yagi K (1979) Assay for lipid peroxides in animal tissues by thiobarbituric acid reaction. Anal Biochem 95:351-358

25. Dwivedi DK, Kumar D, Kwatra M, Pandey SN, Choubey P, Lahkar M, Jangra A (2018) Voluntary alcohol consumption exacerbated high fat diet-induced cognitive deficits by NF-KB-calpain dependent apoptotic cell death in rat hippocampus: ameliorative effect of melatonin. Biomed Pharmacother 108:1393-1403

26. Beutler E, Duron O, Kelly BM (1963) Improved method for the determination of blood glutathione. J Lab Clin Med 61:882-888 
27. Green LC, Wagner DA, Glogowski J, Skipper PL, Wishnok JS, Tannenbaum SR (1982) Analysis of nitrate, nitrite, and [15N] nitrate in biological fluids. Anal Biochem 126:131-138

28. Kim JY, Kim SM, Kim SJ, Lee EY, Kim JR, Cho KH (2017) Consumption of policosanol enhances HDL functionality via CETP inhibition and reduces blood pressure and visceral fat in young and middle-aged subjects. Int $J$ Mol Med 39:889-899

29. Gong $J$ et al (2018) Efficacy and safety of sugarcane policosanol on dyslipidemia: a meta-analysis of randomized controlled trials. Mol Nutr Food Res. https://doi.org/10.1002/mnfr.201700280

30. Faasse S, Braun H, Vos M (2018) The role of NAFLD in cardiometabolic disease: an update. F1000 Res 7:170

31. Patil R, Sood GK (2017) Non-alcoholic fatty liver disease and cardiovascular risk. World J Gastrointest Pathophysiol 8:51-58

32. Musto D, Martorelli L, Russo M, Esposito G, Amato MR, Esposito P, Riegler G (2010) Non-alcoholic hepatic steatosis: the role of policosanols in associated hyperlipidemia. Minerva Gastroenterol Dietol 56:389-395

33. Sharma R, Matsuzaka T, Kaushik MK et al (2019) Octacosanol and policosanol prevent high-fat diet-induced obesity and metabolic disorders by activating brown adipose tissue and improving liver metabolism. Sci Rep 9:5169

34. Recknagel RO (1983) Carbon tetrachloride hepatotoxicity: status quo and future prospects. Trends Pharmacol Sci 4:129-131

35. Recknagel RO, Glende EA, Dolak JA, Waller RL (1989) Mechanisms of carbon tetrachloride toxicity. Pharmacol Ther 43:139-154

36. Sharmila Banu G, Kumar G, Murugesan AG (2009) Effect of ethanolic leaf extract of Trianthema portulacastrum L. On aflatoxin induced hepatic damage in rats. Indian J Clin Biochem 24:414-418

37. Chung APYS, Gurtu S, Chakravarthi S, Moorthy M, Palanisamy UD (2018) Geraniin protects high-fat diet-induced oxidative stress in sprague dawley rats. Front Nutr 5:17

38. Jangra A et al (2016) Honokiol abrogates chronic restraint stress-induced cognitive impairment and depressive-like behaviour by blocking endoplasmic reticulum stress in the hippocampus of mice. Eur J Pharmacol 770:25-32

39. Molina $\mathrm{V}$ et al (2013) Therapeutic effects of policosanol and atorvastatin against global brain ischaemia-reperfusion injury in gerbils. Indian J Pharm Sci 75:635-641

40. Iwakiri Y, Kim MY (2015) Nitric oxide in liver diseases. Trends Pharmacol Sci 36:524-536

\section{Publisher's Note}

Springer Nature remains neutral with regard to jurisdictional claims in published maps and institutional affiliations.

\section{Submit your manuscript to a SpringerOpen ${ }^{\circ}$ journal and benefit from:}

- Convenient online submission

- Rigorous peer review

- Open access: articles freely available online

- High visibility within the field

- Retaining the copyright to your article

Submit your next manuscript at $\boldsymbol{\nabla}$ springeropen.com 